\title{
Scale and accessibility: Implications for the analysis of land use-travel interaction
}

\author{
Mei-Po Kwan ${ }^{\mathrm{a}, *}$, Joe Weber ${ }^{\mathrm{b}, 1}$ \\ ${ }^{a}$ Department of Geography, 1036 Derby Hall, 154 North Oval Mall, Ohio State University, Columbus, OH 43210-1361, USA \\ ${ }^{\mathrm{b}}$ Department of Geography, 202 Farrah Hall, University of Alabama, Box 870322, Tuscaloosa, AL 35487-0322, USA
}

\begin{abstract}
An important methodological issue in accessibility research is how the results are affected by geographical scale. Understanding the scale effect and the associated modifiable areal unit problem (MAUP) is also important for the analysis of land use-travel interaction. Using a distinct type of accessibility measures, namely space-time measures, this study examines whether the relationships among accessibility, land use, and personal and household characteristics vary systematically with geographical scale. Space-time accessibility measures were implemented using an activity-travel diary data set collected in the Portland (Oregon, USA) metropolitan area. Through multilevel models, the study shows that these relationships are scale invariant.
\end{abstract}

(C) 2007 Elsevier Ltd. All rights reserved.

Keywords: Accessibility; Land use; Scale; Space-time measures; Urban travel

\section{Introduction}

Accessibility refers to the ease with which activity locations or urban opportunities can be reached from a particular location or by the individuals at that location. While significant progress has been made in accessibility research in recent years, important methodological issues have not been adequately resolved to date (Kwan \&Weber, 2003). One of the most perplexing problems is how the results of accessibility studies are affected by geographical scale. For accessibility research that is based on zone-based data (e.g., census tracts or traffic analysis zones), the scale effect pertains to the influence of both the size of the zones and the partitioning scheme of these zones on the results. For studies that focus on individual accessibility, the problem is to identify the geographical areas (e.g., neighborhoods, cities, regions) that are most relevant for evaluating the accessibility of different individuals. These areas are not only dissimilar for different individuals, they can also vary greatly in size and the number or types of opportunities they include from one person to another.

\footnotetext{
${ }^{*}$ Corresponding author. Tel.: + 16142929465 ; fax: + 16142926213.

E-mail addresses: kwan.8@osu.edu (M.-P. Kwan), jweber2@bama.ua.edu (J. Weber).

${ }^{1}$ Tel.: + 1205348 5047; fax: + 12053482278 .
} 
Understanding the scale effect and the associated modifiable areal unit problem (MAUP) is particularly important for the analysis of accessibility and land use-travel interaction. It will also provide significant methodological insight into how sustainable land use or transportation can best be achieved. For instance, an association between land use and travel may simply be a result of the association between land use characteristics and the multitude of demographic and transportation characteristics that are associated with travel in the zones defined by the particular zonal scheme (e.g., census tracts) used in a study (Kitamura, Mokhtarian, \& Laidet, 1997). It may largely be the result of the spatial scale and may not imply that land use actually affects travel. Kitamura et al. (1997) indeed found that attitudes are more strongly associated with travel than are land use characteristics. They suggested that land use policies that promote higher densities and mixed land use may not reduce travel unless residents' attitudes also change. Similarly, Snellen, Borgers, and Timmermans (2002) suggest that failure to disentangle the effects of spatial characteristics from personal and household characteristics is an important methodological issue in past studies of land use-travel interaction. Researchers were often not aware of the problems arising from the fact that the observations are made at particular scales and levels of aggregation. Snellen et al.'s (2002) study found that the effect of urban form on various indicators of mobility is negligible, and the land use-travel association observed by others may be a result of the methodology used.

The scale effect and the associated MAUP are well-known problems in geographical literature (e.g., Cao \& Lam, 1997; Fotheringham \& Wong, 1991; Sheppard \& McMaster, 2004). The MAUP refers to the problem that, in the analysis of spatially aggregated data, the results for some analyses depend on the definition of the areal units for which data are reported (Fotheringham, Brunsdon \& Charlton, 2000). The effects of the MAUP can be divided into two components: the scale effect and the zoning effect. The scale effect refers to the variation in results obtained from the same statistical analysis at different levels of spatial resolution. The zoning effect refers to different results arising from the regrouping of zones at a given scale.

There are two different views about how the scale problem should be dealt with. One view holds that since the scale effect is largely the result of the zoning scheme, the best way to resolve the problem is to identify the best zoning scheme or the scale at which the processes being studied operate (Openshaw, 1996). The other, however, holds that the scale problem is the result of erroneous analytical measures that are affected by spatial scale or by the zoning scheme used. Robust analytical measures should be scale-independent or scale-invariant (Tobler, 1989). This study adopts the latter view and holds that there are accessibility measures that are scale independent. Based on the results of a recent study that identifies disaggregate space-time accessibility measures as scale invariant (Weber \& Kwan, 2003), it further examines whether the relationships among accessibility, land use, and personal and household characteristics vary systematically with geographical scale. Space-time accessibility measures were implemented in the study with an activity-travel diary data set collected in the Portland (Oregon, USA) metropolitan area through a GIS-based geocomputational algorithm. The effect of spatial scale on the results was evaluated using multilevel models.

\section{Scale and accessibility}

Accessibility measures were largely evaluated with zone-based data up until the late 1990s. These measures have been constructed for a wide range of zones, such as census tracts or similar units (Haynes, Lovett, \& Sunnenberg, 2003; Helling, 1998; Talen, 1997), neighborhoods (Limanond \& Niemeier, 2003), transport planning zones (Chang, 2003; Kawabata, 2003; Shaw, 1991), political subdivisions of cities (Chang, 2003), and voting precincts (Gimpel \& Schuknecht, 2003). Because these zone-based measures rely on zonal data, they are necessarily constructed at a particular spatial scale. This scale is assumed to be the one at which the relevant spatial process operates.

Recent geographical and urban research has focused on two particular intraurban scales: the local and the regional. At the regional scale, attention has been directed to the effects of urban structure, such as the decentralization of employment and the rise of polycentric cities, the creation of edge cities, and sprawl on accessibility to employment and shopping (Handy, 1993). At this scale it is the division of contemporary cities into polycentric realms or commutersheds that has received attention. Within each area, workers and shoppers are expected to travel to a regional center rather than downtown, possibly making these cities more efficient or equitable than traditional monocentric cities (Gordon, Kumar, \& Richardson, 1989a, 1989b). At this level, 
accessibility reflects the ability to reach major employment centers such as downtowns or edge cities, or shopping opportunities at large malls.

At the local scale, the rise of neo-traditional development (or the new urbanism) has focused attention on the use of residential neighborhood design to modify individual travel behavior (Bookout, 1992). By creating walkable mixed used neighborhoods, it is hoped to encourage shorter trips and greater access to many necessities. The New Urbanist movement, therefore, seeks to shift the spatial scale at which many activities are undertaken. At this scale, accessibility should reflect the ability of people to carry out convenience-based shopping trips without resorting to automobiles.

Bridging these scales could provide more useful measures of accessibility and greater insight into households' travel behaviors. An important approach to date has been to measure access to neighborhood retail and grocery stores (local or neighborhood accessibility) separately from major employment centers and large shopping centers (regional accessibility) (Handy, 1992, 1993; Handy \& Niemeier 1997; Limanond \& Niemeier, 2003). In one case, local accessibility was evaluated at the level of 550 zones (aggregated from census tracts) covering the San Francisco (California, USA) area, while regional accessibility was measured at the superdistrict level (36 zones aggregated from smaller planning zones). This analysis is not limited to two scales of analysis, as Handy (1993) also informally discusses larger areas within the metropolitan area, such as Silicon Valley (California, USA).

There are several difficulties in examining accessibility at these scales. First, the use of particular spatial 'frames' such as census tracts or traffic analysis zones (TAZs) is often problematic because there is no reason why these zones or scales provide natural or reasonable units of analysis. These zones help us structure the world by partitioning cities into discrete zones, yet they do not correspond to individual perception of urban opportunities in cities, such as cognitive opportunity sets (Kwan \& Hong, 1998) or social networks (Carrasco \& Miller, 2006; Hanson \& Pratt, 1988). Zones are used either because data are readily available for those units or because they make for more convenient computation (as in Ritsema van Eck, \& de Jong, 1999), not because they are fundamentally appropriate scales or units. Accessibility analyses may therefore be based on a particular spatial framework largely for convenience, not for sound theoretical reasons.

Second, the zonal spatial frames of these studies also necessitate the use of aggregate accessibility measures. These measures, however, do not allow an evaluation of the role of individual behavior and perception on accessibility. For instance, while two neighbors may share similar accessibilities by virtue of their residential location, aggregate measures do not take into account the effect of their specific activity schedules or time constraints on their mobility. It is not possible to distinguish people from places. However, "an accessibility measure is only appropriate as a performance measure if it is consistent with how residents perceive and evaluate their community" (Handy \& Niemeier, 1997, p.1176). In other words, a suitable definition of accessibility must take into account the elements that matter most to the residents themselves.

A number of important methodological issues also arise with the specification of a particular zonal scheme or scale for analysis. The size and shape of zones used (or using points to represent zones) can also introduce substantial errors into distances measured between locations (Hillsman \& Rhoda, 1978; Pirie, 1979), a point that has been made for accessibility measures (Hewko, Smoyer-Tomic, \& Hodgson, 2002; Pooler, 1987). The MAUP will be a problem for any zone-based accessibility measure (Fotheringham, 1989; Fotheringham et al., 2000; Green \& Flowerdew, 1996; Openshaw, 1996; Tobler 1989). Because of this phenomenon, correlation coefficients tend to increase as larger aggregations are used, and regression coefficients may differ greatly among models calculated using different zones (Fotheringham \& Wong, 1991). The effect of scale on measures of travel behavior and their interpretation has been discussed in detail (Horner \& Murray, 2002; Sultana, 2002). The parameter estimates for models and relationships observed are therefore interdependent with the particular zoning system used, regardless of whether these are natural or arbitrary.

A number of approaches have been suggested for handling the MAUP, each with implications for measuring accessibility. One approach would be to design spatial zones that are meaningful or appropriate for the analysis being carried out (Openshaw, 1978). From this perspective, "the MAUP will disappear once geographers know what the areal objects they wish to study are" (Openshaw, 1996, p. 65), although it seems unlikely that truly objective optimal zoning schemes can be arrived at (Fotheringham, 1989). As the MAUP exists largely because of zonal schemes, it has been argued that the use of disaggregate data, or representing data with continuous surfaces, is the best way to avoid the problem (Fotheringham, 1989; Martin, 1996). 
However, it can be argued that surface representations are not effective means for resolving the MAUP because "the continuous approximation of discrete information merely reintroduces other sorts of error, inaccuracy, and distortion" (Openshaw, 1996, p. 67).

An alternative view about the nature of the MAUP and the scale problem is that the MAUP stems not from using inappropriate zones, but from using inappropriate methods, ones that are based on the use of zonal data and are therefore scale-dependent (Tobler, 1989). According to this view, the use of GIS to define new zonal units or sets of zones at multiple scales does not fully eliminate the problem. Frame-independent and scaleinvariant methods that do not produce results that are dependent on particular sets of zones or the spatial scale should be developed and used instead. Ideally, such measures should also correspond to conceptual spaces as well. This study follows this view proposed by Waldo Tobler (1989). It evaluates the properties of a distinct type of accessibility measures, namely space-time measures, through a study using an activity-travel diary data set collected in Portland (Oregon, USA). It suggests that these measures are frame independent and scale invariant because they define spaces in terms of the daily activities and travel of individuals. For this reason, the paper argues, space-time accessibility measures are not only conceptually more meaningful, their use may help alleviate the MAUP that affects the results of any zone-based accessibility analysis.

\section{Space-time accessibility measures}

The foundation for space-time measures of individual accessibility is Torsten Hägerstrand's (1970) time-geographic framework. It provides a means for modeling the possibilities for and limits to the movements of an individual through space and time. These movements are limited by at least three sets of constraints, which reflect the speed at which mobility is possible (physical constraints), the fact that many areas are effectively off-limits to certain (or all) people due to administrative regulations or social control (authority constraints), and the need for people to coordinate movement with others for a variety of joint activities located at different times and places (coupling constraints).

Besides these three categories of classic time-geographic constraints, other constraints (such as travel costs and limited physical access) can also be taken into account by the space-time measures of individual accessibility. These constraints limit a person's freedom and define a space-time path that can be traversed by that individual during the course of a day.

Accessibility measures based on this time-geographic conception of individual movements can be derived through identifying those areas an individual can reach during the day and the opportunities available within these areas (Kwan, 1998, 1999a; Miller, 1991; Recker, Chen, \& McNally, 2001; Weber, 2003; Weber \& Kwan, $2002,2003)$. Since the location and duration of some activities are fixed and beyond the control of the individual-for example, work or doctor's appointments - these activities (called "fixed activities") provide a spatial and temporal framework for each person's daily schedule, with flexible activities fit in when and where practicable. Some activities are flexible in that an individual has some control over when and where these activities take place (e.g., such as stopping at a gas station, or renting a DVD). The potential freedom of an individual to maneuver between fixed activities and gain access to flexible activities can be used as a measure of accessibility. The greater the time between successive fixed activities and the greater the number of potential flexible activities nearby, the greater their accessibility.

Because there is no readily available procedure for identifying the urban opportunities that a person can reach within his/her space-time constraints, recent studies have operationalized and implemented space-time accessibility measures within GIS using dedicated geocomputational algorithms (e.g., Kim \& Kwan, 2003; Kwan, 2004). Further, this approach requires detailed disaggregate data. Detailed travel and activity data must be available to show the locations, movements and activities of individuals. Individual accessibility was therefore evaluated in this study using the Household Activity and Travel Behavior Survey data set collected in the Portland (Oregon, USA) metropolitan area in 1994 and 1995 (Cambridge Systematics, 1996) (Fig. 1). ${ }^{2}$

\footnotetext{
${ }^{2}$ The Portland metropolitan area, however, is not a typical US city in terms of the evenness of distribution of urban opportunities. The urban growth boundary, which was created in 1979 in an attempt to limit urban sprawl and preserve farmland, and the network of lightrail lines in the area have considerably increased the region's land use density and have led to a relatively high concentration of urban opportunities in downtown Portland (Abbott, 2001).
} 


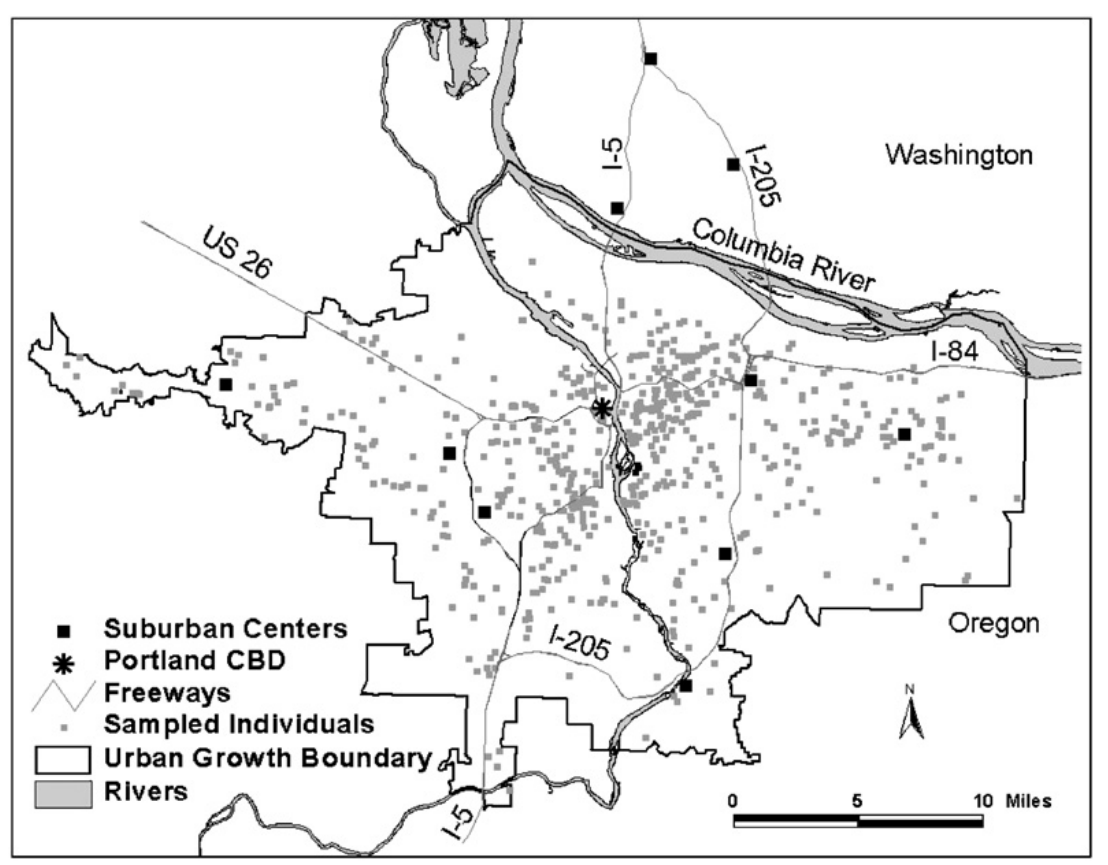

Fig. 1. The study area.

This survey collected activity-travel diary data for 10,084 people from 4451 households for 2 days, including all out-of-home activities and in-home activities lasting more than $30 \mathrm{~min}$.

Although the Portland data set included individuals traveling by a variety (and combination) of transportation modes, only those traveling by private automobiles were used in this research. This ensures that variations in accessibility are not due to transport mode while greatly simplifying the computation of accessibility, as no scheduling considerations are involved. ${ }^{3}$ The individuals used for this research were further restricted to those adults living inside the metro urban growth boundary with at least one fixed activity (in or out of the home) each day, and with all activities taking place within the Portland MSA counties on weekdays. As a result of these selection procedures, 755 individuals from 598 households were chosen and used in this research. These individuals engaged in an average of six activities each day. This sample is split roughly equally between men and women (52.7\% male) and is overwhelmingly $(94.7 \%)$ white. Employment status of the individuals sampled is slightly more diverse, with $77.6 \%$ employed full time, $13.7 \%$ part time, $2.6 \%$ are full time homemakers, $1.5 \%$ retired, and $4.3 \%$ are not employed.

Several methods of computing space-time accessibility within GIS exist (Kwan, 2004). This study used a method that is based on Weber and Kwan $(2002,2003)$. A detailed street network was required to allow the computation of accurate travel times within the city, and this was obtained using the US Census Bureau TIGER street network for the study area, with free flow driving times matched to this network from local planning data. Peak period travel time estimated from these data allows more accurate estimates of reduced mobility during rush hour conditions (treated here as 4 to $6 \mathrm{PM}) .{ }^{4}$ These activity and network data were used

\footnotetext{
${ }^{3}$ As only those who traveled by private automobiles were selected for the study, the analysis focuses only on accessibility by car. Individuals who depend on other modes of transport (e.g., public transit) were not included in the study because considerable resources and efforts are required to construct a detailed temporal multi-modal transport network (including bus and light-rail schedules) for computational purposes. However, given the additional spatial and temporal constraints imposed by the schedules and routes of public transit, the PPAs for individuals who do not primarily rely on private cars will likely be smaller and their space-time accessibility will be lower than those who rely primarily on private automobiles.

${ }^{4}$ Selecting only evening hours allows the effects of congestion to be more easily isolated as observed reductions in accessibility can be attributed solely to the evening peak travel period. This allows the direct comparison of congestion effects among individuals and areas without having to control for time of day. Because most discretionary travel occurs during the afternoon and evening hours (Kwan, 1999b), this period can also be expected to have a much greater impact on accessibility than morning congestion, making evening hours more useful for assessing the effects of congestion.
} 
to evaluate each individual's space-time accessibility, which are based on identifying the area an individual can move about within the time available to him or her (also known as their potential path area or PPA). This area contains all possible combinations of routes a person could traverse while traveling between successive fixed activities. Only those potential activities that can be found within the PPA are available to them.

Five space-time accessibility measures were implemented and tested in this research, all derived from each individual's daily PPAs. The simplest of these measures is the number of miles of street present within an individual's daily potential path areas (labeled Miles in this research). A second measure (called Opportunities) represents the number of potential activities present within their PPA. These opportunities were represented by a GIS database containing the centroids of 27,749 commercial and industrial land parcels in the study area. This GIS database provides the needed land use data and was maintained by the government of the Portland metropolitan region (Metro). The square footage of opportunity parcels within each PPA (called Area) was used as a measure to represent the differing size of individual opportunities, while another measure took into account the presence of high rise buildings in downtown Portland by weighting the area of parcels in that location (Weighted Opportunities). Finally, a fifth measure incorporated authority constraints by excluding all opportunities reachable late at night and early in the morning (after 9 PM and before 6 AM). This Daytime Opportunities measure, therefore, incorporates the fact that unlimited nighttime mobility will not necessarily increase accessibility if there are no possible activities.

\section{Evaluating accessibility at multiple scales}

The importance of spatial scale to individual accessibility patterns was examined by carrying out an analysis on the relationship between access and explanatory characteristics at a range of spatial scales. These include gender, age, race, whether the individual is the head of their household, relation to the head of their household, household size, number of children in the household, the individual's employment status (not working, part time, full time), number of hours worked per week, and household income (within $\$ 5000$ intervals). Each of these variables can be expected to have an influence on accessibility (Weber \& Kwan, 2003). Distance (measured by free flow driving times) from each individual's home to downtown Portland and each of 11 regional centers in the city's 2040 Growth Plan (Metro, 1997) was also included. These centers are part of a hierarchy defined for the Portland metropolitan area, and are intended to be large mixed land use developments, representing a concentration of employment, retail, and recreational opportunities.

These variables were first used to predict each of the five accessibility measures at the metropolitan level using forward stepwise regression. The results of the best fitting models are shown in Table 1. In addition to the significant parameter estimates, $F$ tests for each of the models indicate that they are all significant at the $99 \%$ confidence level. The small $R^{2}$ values indicate that the independent variables account for only a small portion of the variation in standardized accessibilities, indicating that there is a high degree of variation among individuals. Since the purpose of the study is to evaluate the effect of scale on the analytical results, these models should be treated as a baseline for comparison with the results of the multilevel models presented below. These multilevel models were estimated using the MLwin software package. Further, several important relationships exist between these variables and access. As can be seen from the table, only three of the distance variables were present in the final models, representing distance to the Portland CBD, the Clackamas Town Center, and the I-84/205 center. Given the strongly monocentric distribution of potential activities in the study area, the importance of the Portland CBD was surprisingly small, as of the five measures only the number of activities accessible (Opportunities) declined with distance from this location.

While individual accessibilities are related to both socioeconomic variables and distance, these relationships were evaluated at the scale of the entire metropolitan area. There is, therefore, reason to expect that the relationships between individual or household characteristics and accessibility may vary depending on the geographic scale at which it is evaluated. Individual accessibility in Portland was, therefore, re-examined using multilevel modeling to identify whether the observed relationships vary by scale. This extends the baseline linear regression models to multiple spatial scales, evaluating relationships among individuals as well as among places (Bullen, Jones, \& Duncan, 1997; Goldstein, 1998; Jones \& Duncan, 1996; Kreft \& de Leeuw, 1998). This allows a 'social and spatial decomposition' (Subramanian, Duncan, \& Jones, 2001) of the relative roles of individual level variables and area level variables. 
Table 1

Regression results

\begin{tabular}{|c|c|c|c|c|c|c|c|}
\hline $\begin{array}{l}\text { Dependent } \\
\text { variable }\end{array}$ & Independent variable & Coefficient & Std error & $\begin{array}{l}\text { Standardized } \\
\text { coefficient }\end{array}$ & $\begin{array}{l}\text { Significance } \\
\text { level }\end{array}$ & $R^{2}$ & $\begin{array}{l}\text { Adjusted } \\
R^{2}\end{array}$ \\
\hline Miles & $\begin{array}{l}\text { Constant } \\
\text { Distance to Clackamas } \\
\text { Center } \\
\text { Hours worked } \\
\text { Household size }\end{array}$ & $\begin{array}{r}201.11 \\
-1.63 \\
-1.25 \\
-5.90\end{array}$ & $\begin{array}{r}16.41 \\
0.35 \\
\\
0.28 \\
2.74\end{array}$ & $\begin{array}{l}-0.17 \\
-0.16 \\
-0.08\end{array}$ & $\begin{array}{l}0.000 \\
0.000 \\
0.000 \\
0.031\end{array}$ & 0.055 & 0.051 \\
\hline Opportunities & $\begin{array}{l}\text { ConstantDistance to } \\
\text { Portland CBD } \\
\text { Distance to I- } 84 / 205 \text { Center } \\
\text { Hours worked }\end{array}$ & $\begin{array}{l}183.19 \\
-1.19 \\
-1.37 \\
-0.93\end{array}$ & $\begin{array}{r}10.70 \\
0.41 \\
0.37 \\
0.22\end{array}$ & $\begin{array}{l}-0.13 \\
-0.17 \\
-0.15\end{array}$ & $\begin{array}{l}0.000 \\
0.004 \\
0.000 \\
0.000\end{array}$ & 0.094 & 0.091 \\
\hline Area & $\begin{array}{l}\text { Constant } \\
\text { Distance to I- } 84 / 205 \text { Center } \\
\text { Hours worked }\end{array}$ & $\begin{array}{r}175.40 \\
-1.94 \\
-1.02\end{array}$ & $\begin{array}{r}11.58 \\
0.31 \\
0.25\end{array}$ & $\begin{array}{l}-0.22 \\
-0.14\end{array}$ & $\begin{array}{l}0.000 \\
0.000 \\
0.000\end{array}$ & 0.066 & 0.063 \\
\hline $\begin{array}{l}\text { Weighted } \\
\text { opportunities }\end{array}$ & $\begin{array}{l}\text { Constant } \\
\text { Distance to I-84/205 Center } \\
\text { Hours worked }\end{array}$ & $\begin{array}{r}174.08 \\
-1.91 \\
-1.00\end{array}$ & $\begin{array}{r}11.33 \\
0.31 \\
0.24\end{array}$ & $\begin{array}{l}-0.22 \\
-0.14\end{array}$ & $\begin{array}{l}0.000 \\
0.000 \\
0.000\end{array}$ & 0.067 & 0.064 \\
\hline $\begin{array}{l}\text { Daytime } \\
\text { opportunities }\end{array}$ & $\begin{array}{l}\text { Constant } \\
\text { Distance to Clackamas } \\
\text { Center } \\
\text { Hours worked }\end{array}$ & $\begin{array}{r}281.89 \\
-1.83 \\
-3.90\end{array}$ & $\begin{array}{r}22.27 \\
0.57 \\
0.44\end{array}$ & $\begin{array}{l}-0.11 \\
-0.31\end{array}$ & $\begin{array}{l}0.000 \\
0.001 \\
0.000\end{array}$ & 0.103 & 0.1 \\
\hline
\end{tabular}

The use of multilevel methodologies is based on choosing the most appropriate scale(s) of analysis. A number of spatial scales can be expected to be important to accessibility within cities. One scale is created by political boundaries, that are likely to be related to socioeconomic composition as well as housing and land use characteristics. For these reasons, several zonal schemes were created to attempt to represent the importance of these units. These boundaries were used to construct the first set of zones, called City. Individuals were grouped according to residence within the city of Portland, other Multnomah county jurisdictions, Clackamas county suburbs, unincorporated areas within Clackamas County, Washington County suburbs, and unincorporated areas within Washington County. Another zonal scheme was used to test for the importance of location within particular school districts. This scheme (named School) groups individuals according to location within the Portland school district, other Multnomah county districts, Clackamas County districts, or Washington County districts.

In addition to political boundaries, economic divisions of Portland should also be recognized in the creation of scales. For this purpose, discrete commutersheds that centered on separate urban centers were used to identify functional regions within Portland. The 2040 Growth Plan for the Portland metropolitan area was used to identify major suburban centers (Metro, 1997). Commutersheds were created by measuring driving times from each regional center to block group centroids, and then assigning each block group to the nearest center. These block groups were then aggregated to create commutersheds and used to group individuals. This set of zones was named Commutershed.

Two distinct approaches were used to construct useful neighborhood zones. One set of zones is based on Abbott's (1983) discussion of Portland's neighborhoods (called Abbott), which resulted in four zones. These include older downtown neighborhoods, early 20th century neighborhoods, later automobile oriented residential areas, and hilltop developments. A second approach to represent neighborhoods was based on those designated by Metro. These comprise 259 subdivisions of the area within the Portland urban growth boundary, and can be expected to be more sensitive to variations within the city of Portland as well as suburban areas (which Abbott largely ignored). Because sampled individuals were present in relatively few of these neighborhoods, they were grouped within aggregations of these neighborhood zones. In order to group individuals, these 259 neighborhood units were aggregated using physical features, freeways and political 
boundaries, based in part on field observations of the Portland area. This took into account the presence of barriers to mobility such as the West Hills and the Willamette River, as well as the tendency of several freeways to isolate neighborhoods. Two separate sets of neighborhoods were created with these aggregations. The first (NBO1) contains 21 zones, while the second (NBO2) has 12.

In addition to these zones, four sets of completely artificial zones were created at different scales to test for accessibility variations. The study area was subdivided into randomly created zones at a variety of scales. Sets of Thiessen polygons were created with 10, 20, 30, and 40 zones (called Thiessen 10, 20, 30, and 40). These polygons were created around randomly selected block group centroids within GIS (Horner \& Murray, 2002; Murray \& Gottsegen, 1997). The study individuals were then grouped within these areas as with the more conventional zones.

Rather than using a single set of zones and exploring the effects of adding new variables to models, as is common in most multilevel modeling research, the goal here is to examine relationships among a relatively small set of variables at a range of spatial scales. The five original regression models (one for each accessibility measure) were tested for each of the 10 sets of zones, resulting in a total of 50 models (Table 2). At each scale and for each measure, the values of the constant and coefficients have remained surprisingly similar to their single-level regression values, indicating that the effects of distance, hours worked, and household size on individual accessibility are independent of spatial scale. The major exception is the Daytime Opportunities measure, for which there is some difference in parameter values at the scale of political jurisdictions (City). Distance to the Clackamas Town Center is considerably more important when accessibility is evaluated at the scale of political jurisdictions. Likewise, the number of hours worked has less than half the effect on accessibility using this set of zones than with all others. This is likely due to the fact that five of the six zones at the scale of CITY are suburban or unincorporated areas, and such urban-versus-suburban division of the zonal scheme tends to emphasize the impact of the distance to the Clackamas Town Center on individual accessibility (measured as Daytime Opportunities) more than work hours.

All parameters of the models have a ratio of estimate to standard error greater than two, the value commonly used as a rule of thumb for accepting the significance of these parameters within multilevel modeling. In addition to the parameter estimates, the tables for these models also include the individual level and zonal level variances. These show variation between individuals as well as between areas. Further, the existence of random slopes, which allow the relationships between individual accessibility and explanatory variables to vary among areas, was tested for, but none were found. Because the individual and contextual variables used were selected with a single level regression model that treats the entire Portland metropolitan areas as a single zone, they may not reflect relationships that exist at more local scales. For this reason, additional models were estimated for the NBO1 and NBO2 neighborhood zones to identify whether other variables appear at more local scales, but no models were found that provide a higher level of explanation than those found using stepwise regression.

\section{Conclusions}

The use of multilevel modeling to explain accessibility offers the opportunity to find geographic variations in accessibility previously invisible with single level models. However, a striking result of the use of this methodology with space-time accessibility measures is the scale independence or invariance of the observed relationships. With the limited exception of the effects of explanatory variables on the Daytime Opportunities measure of accessibility, the observed relationships show no substantial variation at different geographic scales. Given the importance of individual and household attributes to accessibility values, and the fact that it has been shown that individual accessibility bears little relationship to the characteristics of neighborhood zones (Weber \& Kwan, 2003), this is not particularly surprising. It also suggests that because accessibility as evaluated by space-time measures is clearly a property linked to individual characteristics and activity behavior, it is unlikely to differ among geographic areas within the city. The relationship between the number of hours worked and the area of opportunities accessible is therefore constant across the city. In part this may be explained by the size of the data set, as this research uses what can be considered a relatively small sample size for multilevel research. It is likely that a much larger data set (containing several thousand individuals) 
Table 2

Results of multilevel models at multiple scales

\begin{tabular}{|c|c|c|c|c|c|c|c|c|c|c|}
\hline & \multicolumn{2}{|l|}{ City } & \multicolumn{2}{|l|}{ School } & \multicolumn{2}{|c|}{ Commutershed } & \multicolumn{2}{|l|}{ Abbott } & \multicolumn{2}{|l|}{ NBO1 } \\
\hline & Estimate & $\begin{array}{l}\text { Estimate/ } \\
\text { Std. error }\end{array}$ & Estimate & $\begin{array}{l}\text { Estimate/ } \\
\text { Std. error }\end{array}$ & Estimate & $\begin{array}{l}\text { Estimate/ } \\
\text { Std. error }\end{array}$ & Estimate & $\begin{array}{l}\text { Estimate/ } \\
\text { Std. error }\end{array}$ & Estimate & $\begin{array}{l}\text { Estimate/ } \\
\text { Std. error }\end{array}$ \\
\hline \multicolumn{11}{|l|}{ Miles } \\
\hline Intercept & 197.47 & 10.89 & 201.11 & 12.29 & 201.42 & 11.83 & 201.11 & 12.29 & 200.69 & 11.84 \\
\hline Distance to Clackamas Center & -1.60 & -4.03 & -1.63 & -4.65 & -1.60 & -4.17 & -1.63 & -4.65 & -1.58 & -4.16 \\
\hline Hours worked & -1.24 & -4.53 & -1.25 & -4.57 & -1.26 & -4.61 & -1.25 & -4.57 & -1.26 & -4.60 \\
\hline Household size & -5.92 & -2.17 & -5.90 & -2.16 & -6.14 & -2.24 & -5.90 & -2.16 & -6.16 & -2.25 \\
\hline Individual level variance & 10371.04 & 19.37 & 10414.78 & 19.43 & 10369.09 & 19.33 & 10414.79 & 19.43 & 10337.41 & 19.18 \\
\hline Area level variance & 53.80 & 0.63 & 0.00 & 0.00 & 44.09 & 0.57 & 0.00 & 0.00 & 74.78 & 0.68 \\
\hline-2 Log Likelihood & 9126.54 & & 9127.09 & & 9126.43 & & 9127.09 & & 9126.24 & \\
\hline Reduction from null & 34.48 & & 41.00 & & 36.75 & & 41.34 & & 36.64 & \\
\hline \multicolumn{11}{|l|}{ Opportunities } \\
\hline Intercept & 183.11 & 17.17 & 183.10 & 17.17 & 183.40 & 16.71 & 183.10 & 17.17 & 181.36 & 16.17 \\
\hline Distance to CBD & -1.19 & -2.89 & -1.19 & -2.89 & -1.21 & -2.79 & -1.19 & -2.89 & -1.11 & -2.35 \\
\hline Distance to I-84/205 Center & -1.37 & -3.76 & -1.37 & -3.76 & -1.35 & -3.52 & -1.37 & -3.76 & -1.37 & -3.31 \\
\hline Hours worked & -0.93 & -4.23 & -0.93 & -4.23 & -0.93 & -4.25 & -0.93 & -4.23 & -0.93 & -4.24 \\
\hline Individual level variance & 6925.19 & 19.43 & 6925.19 & 19.43 & 6915.62 & 19.33 & 6925.19 & 19.43 & 6866.64 & 19.18 \\
\hline Area level variance & 0.00 & 0.00 & 0.00 & 0.00 & 9.64 & 0.24 & 0.00 & 0.00 & 56.19 & 0.75 \\
\hline-2 Log Likelihood & 8819.00 & & 8819.00 & & 8818.94 & & 8819.00 & & 8817.92 & \\
\hline Reduction from null & 39.25 & & 48.01 & & 46.92 & & 51.05 & & 47.57 & \\
\hline \multicolumn{11}{|l|}{ Area } \\
\hline Intercept & 175.40 & 15.17 & 175.40 & 15.17 & 175.94 & 14.79 & 175.40 & 15.17 & 174.64 & 14.37 \\
\hline Distance to I-84/205 Center & -1.94 & -6.22 & -1.94 & -6.22 & -1.95 & -5.95 & -1.94 & -6.22 & -1.91 & -5.60 \\
\hline Hours worked & -1.02 & -4.08 & -1.02 & -4.08 & -1.02 & -4.09 & -1.02 & -4.08 & -1.02 & -4.11 \\
\hline Individual level variance & 8839.74 & 19.43 & 8839.74 & 19.43 & 8826.65 & 19.33 & 8839.74 & 19.43 & 8767.93 & 19.18 \\
\hline Area level variance & 0.00 & 0.00 & 0.00 & 0.00 & 13.09 & 0.25 & 0.00 & 0.00 & 68.62 & 0.72 \\
\hline-2 Log Likelihood & 9003.29 & & 9003.29 & & 9003.21 & & 9003.29 & & 9002.26 & \\
\hline Reduction from null & 35.68 & & 42.85 & & 37.69 & & 46.61 & & 38.28 & \\
\hline \multicolumn{11}{|l|}{ Weighted opportunities } \\
\hline Intercept & 174.08 & 15.40 & 174.08 & 15.40 & 174.69 & 14.92 & 174.08 & 15.40 & 173.49 & 14.58 \\
\hline Distance to I-84/205 center & -1.91 & -6.26 & -1.91 & -6.26 & -1.92 & -5.93 & -1.91 & -6.26 & -1.88 & -5.63 \\
\hline Hours worked & -1.00 & -4.10 & -1.00 & -4.10 & -1.00 & -4.12 & -1.00 & -4.10 & -1.01 & -4.14 \\
\hline Individual level variance & 8453.43 & 19.43 & 8453.43 & 19.43 & 8437.94 & 19.33 & 8453.43 & 19.43 & 8382.24 & 19.18 \\
\hline Area level variance & 0.00 & 0.00 & 0.00 & 0.00 & 15.59 & 0.30 & 0.00 & 0.00 & 67.38 & 0.73 \\
\hline-2 Log Likelihood & 8969.56 & & 8969.56 & & 8969.45 & & 8969.56 & & 8968.42 & \\
\hline Reduction from null & 34.61 & & 42.44 & & 37.76 & & 46.00 & & 38.44 & \\
\hline \multicolumn{11}{|l|}{ Daytime opportunities } \\
\hline Intercept & 277.71 & 12.00 & 281.89 & 12.68 & 277.33 & 11.89 & 281.89 & 12.68 & 279.02 & 11.55 \\
\hline
\end{tabular}




\begin{tabular}{|c|c|c|c|c|c|c|c|c|c|c|}
\hline Distance to Clackamas Center & -3.89 & -8.89 & -1.83 & -3.23 & -1.69 & -2.76 & -1.83 & -3.23 & -1.73 & -2.68 \\
\hline Hours worked & -1.73 & -2.95 & -3.90 & -8.91 & -3.90 & -8.92 & -3.90 & -8.91 & -3.90 & -8.92 \\
\hline Individual level variance & 27289.74 & 19.39 & 27316.32 & 19.43 & 27219.54 & 19.33 & 27316.33 & 19.43 & 26956.57 & 19.18 \\
\hline Area level variance & 29.11 & 0.24 & 0.00 & 0.00 & 94.18 & 0.49 & 0.00 & 0.00 & 352.86 & 1.03 \\
\hline-2 Log Likelihood & 9855.08 & & 9855.10 & & 9854.66 & & 9855.10 & & 9853.02 & \\
\hline \multirow{2}{*}{ Reduction from null } & \multicolumn{2}{|l|}{$\mathrm{NBO} 2$} & \multicolumn{2}{|c|}{ Thiessen 10} & \multicolumn{2}{|c|}{ Thiessen 20} & \multicolumn{2}{|c|}{ Thiessen 30} & \multicolumn{2}{|c|}{ Thiessen 40} \\
\hline & Estimate & $\begin{array}{l}\text { Estimate/ } \\
\text { Std. error }\end{array}$ & Estimate & $\begin{array}{l}\text { Estimate/ } \\
\text { Std. error }\end{array}$ & Estimate & $\begin{array}{l}\text { Estimate/ } \\
\text { Std. error }\end{array}$ & Estimate & $\begin{array}{l}\text { Estimate/ } \\
\text { Std. error }\end{array}$ & Estimate & $\begin{array}{l}\text { Estimate/ } \\
\text { Std. error }\end{array}$ \\
\hline \multicolumn{11}{|l|}{ Miles } \\
\hline Intercept & 201.83 & 11.84 & 201.11 & 12.29 & 202.57 & 12.15 & 200.72 & 11.98 & 201.11 & 12.29 \\
\hline Distance to Clackamas Center & -1.63 & -4.22 & -1.63 & -4.65 & -1.68 & -4.57 & -1.62 & -4.32 & -1.63 & -4.65 \\
\hline Hours worked & -1.26 & -4.59 & -1.25 & -4.57 & -1.25 & -4.57 & -1.25 & -4.55 & -1.25 & -4.57 \\
\hline Household size & -6.02 & -2.20 & -5.90 & -2.16 & -5.88 & -2.15 & -5.97 & -2.17 & -5.90 & -2.16 \\
\hline Individual level variance & 10361.74 & 19.29 & 10414.79 & 19.43 & 10387.06 & 19.23 & 10357.88 & 19.12 & 10414.79 & 19.43 \\
\hline Area level variance & 54.66 & 0.62 & 0.00 & 0.00 & 28.80 & 0.33 & 57.26 & 0.51 & 0.00 & 0.00 \\
\hline-2 Log Likelihood & 9126.62 & & 9127.09 & & 9127.03 & & 9126.79 & & 9127.09 & \\
\hline Reduction from null & 37.11 & & 38.87 & & 39.31 & & 35.01 & & 39.31 & \\
\hline Intercept & 182.65 & 16.01 & 183.11 & 17.17 & 185.29 & 16.33 & 182.84 & 17.03 & 183.11 & 17.17 \\
\hline Distance to CBD & -1.13 & -2.39 & -1.19 & -2.89 & -1.11 & -2.30 & -1.17 & -2.80 & -1.19 & -2.89 \\
\hline Distance to I-84/205 Center & -1.39 & -3.27 & -1.37 & -3.76 & -1.51 & -3.42 & -1.37 & -3.69 & -1.37 & -3.76 \\
\hline Hours worked & -0.93 & -4.23 & -0.93 & -4.23 & -0.93 & -4.24 & -0.93 & -4.23 & -0.93 & -4.23 \\
\hline Individual level variance & 6880.39 & 19.28 & 6925.19 & 19.43 & 6866.48 & 19.22 & 6916.56 & 19.13 & 6925.19 & 19.43 \\
\hline Area level variance & 46.52 & 0.73 & 0.00 & 0.00 & 62.45 & 0.83 & 8.65 & 0.13 & 0.00 & 0.00 \\
\hline-2 Log Likelihood & 8818.29 & & 8819.00 & & 8818.22 & & 8818.99 & & 8819.00 & \\
\hline Reduction from null & 47.20 & & 50.95 & & 51.88 & & 44.77 & & 56.12 & \\
\hline \multicolumn{11}{|l|}{ Area } \\
\hline Intercept & 176.16 & 14.24 & 175.40 & 15.17 & 178.59 & 14.46 & 174.97 & 14.85 & 175.40 & 15.17 \\
\hline Distance to I-84/205 Center & -1.98 & -5.53 & -1.94 & -6.22 & -2.07 & -5.75 & -1.93 & -5.88 & -1.94 & -6.22 \\
\hline Hours worked & -1.02 & -4.11 & -1.02 & -4.08 & -1.02 & -4.10 & -1.01 & -4.07 & -1.02 & -4.08 \\
\hline Individual level variance & 8779.04 & 19.28 & 8839.74 & 19.43 & 8770.24 & 19.22 & 8803.62 & 19.12 & 8839.74 & 19.43 \\
\hline Area level variance & 61.93 & 0.76 & 0.00 & 0.00 & 74.52 & 0.79 & 36.18 & 0.39 & 0.00 & 0.00 \\
\hline-2 Log Likelihood & 9002.42 & & 9003.29 & & 9002.67 & & 9003.11 & & 9003.29 & \\
\hline Reduction from null & 34.02 & & 39.46 & & 40.67 & & 35.73 & & 43.45 & \\
\hline \multicolumn{11}{|l|}{ Weighted opportunities } \\
\hline Intercept & 174.94 & 14.42 & 174.08 & 15.40 & 177.99 & 14.59 & 173.55 & 15.00 & 174.08 & 15.40 \\
\hline Area level variance & 62.55 & 0.78 & 0.00 & 0.00 & 84.69 & 0.89 & 42.48 & 0.47 & 0.00 & 0.00 \\
\hline-2 Log Likelihood & 8968.60 & & 8969.56 & & 8968.63 & & 8969.28 & & 8969.56 & \\
\hline
\end{tabular}


Table 2 (continued)

\begin{tabular}{|c|c|c|c|c|c|c|c|c|c|c|}
\hline & \multicolumn{2}{|l|}{$\mathrm{NBO} 2$} & \multicolumn{2}{|c|}{ Thiessen 10} & \multicolumn{2}{|c|}{ Thiessen 20} & \multicolumn{2}{|c|}{ Thiessen 30} & \multicolumn{2}{|c|}{ Thiessen 40} \\
\hline & Estimate & $\begin{array}{l}\text { Estimate/ } \\
\text { Std. error }\end{array}$ & Estimate & $\begin{array}{l}\text { Estimate/ } \\
\text { Std. error }\end{array}$ & Estimate & $\begin{array}{l}\text { Estimate/ } \\
\text { Std. error }\end{array}$ & Estimate & $\begin{array}{l}\text { Estimate/ } \\
\text { Std. error }\end{array}$ & Estimate & $\begin{array}{l}\text { Estimate/ } \\
\text { Std. error }\end{array}$ \\
\hline Reduction from null & 34.60 & & 39.56 & & 41.36 & & 35.98 & & 43.99 & \\
\hline \multicolumn{11}{|l|}{ Daytime opportunities } \\
\hline Intercept & 282.27 & 12.23 & 281.89 & 12.68 & 283.83 & 11.60 & 280.56 & 12.32 & 281.89 & 12.68 \\
\hline Distance to Clackamas Center & -1.84 & -3.03 & -1.83 & -3.23 & -1.84 & -2.71 & -1.81 & -3.03 & -1.83 & -3.23 \\
\hline Hours worked & -3.90 & -8.91 & -3.90 & -8.91 & -3.89 & -8.92 & -3.89 & -8.88 & -3.90 & -8.91 \\
\hline Individual level variance & 27228.43 & 19.29 & 27316.32 & 19.43 & 27003.04 & 19.21 & 27197.50 & 19.12 & 27316.33 & 19.43 \\
\hline Area level variance & 89.68 & 0.43 & 0.00 & 0.00 & 360.63 & 1.06 & 119.47 & 0.42 & 0.00 & 0.00 \\
\hline -2 Log Likelihood & 9854.91 & & 9855.10 & & 9854.13 & & 9854.91 & & 9855.10 & \\
\hline Reduction from null & 79.43 & & 80.39 & & 78.41 & & 78.48 & & 81.31 & \\
\hline
\end{tabular}


would greatly improve the utility of multilevel modeling as well as allowing for a much finer spatial resolution of the zones.

These findings have important implications for the deployment of particular spatial scales in accessibility studies and transportation modeling. Conceptually, space-time measures identify areas that are relevant to individuals, and so avoid the use of arbitrary spatial frames or zones. Methodologically, space-time measures avoid many of the pitfalls of aggregate measures. Space-time measures are scale or frame independent, whether they are based on existing boundaries or are defined arbitrarily, and this characteristic of being frame independent suggests that the scale effect and the MAUP is not a problem for accessibility analysis when using space-time measures. While the use of multilevel modeling to avoid ecological fallacies and minimize MAUP effects is an appealing methodology, and offers the potential to identify complex, scale-contingent geographies, it does not appear to be necessary or useful with space-time accessibility measures. While the idea of measuring local and regional accessibility is also appealing, the use of space-time measures renders this approach superfluous, as people define their own spaces and tie together different spatial scales through their daily movements and activities, which may be independent of any areal units. Due to their scale and frame independence, the single level stepwise regression appears adequate.

These results also have significant implications for sustainable land use and transportation policy that attempts to modify travel behavior through creating more areas with mixed land use at the local scale. Because there appears little sensitivity to scale, neo-urbanist attempts to shift the focus of commuting or shopping trips from the regional to local scales, or from metropolitan to regional scales by emphasizing urban villages, are likely to be ineffective. A person's 'individual city' will likely span a variety of these scales. Not surprisingly, there is no compelling evidence that people actually commute, shop, or play within polycentric centers (Fujii \& Hartshorn, 1995; Pickus \& Gober, 1988), and the effectiveness of the new urbanism strategy remains uncertain (Boarnet \& Crane, 2001). The land use-travel association observed by recent studies may be a result of the methodology used, and land use policies that promote higher densities and mixed land use may not reduce travel unless residents' attitudes also change (Kitamura et al., 1997; Snellen et al., 2002).

\section{References}

Abbott, C. (1983). Portland: Planning, politics, and growth in a twentieth-century city. Lincoln: University of Nebraska Press.

Abbott, C. (2001). Greater Portland: Urban life and landscape in the Pacific Northwest. Philadelphia: University of Pennsylvania Press. Boarnet, M. G., \& Crane, R. (2001). Travel by design: The influence of urban form on travel. Oxford: Oxford University Press.

Bookout, L. W. (1992). Neotraditional town planning: A new vision for the suburbs? Urban Land 51, 20-26.

Bullen, N., Jones, K., \& Duncan, C. (1997). Modelling complexity: Analysing between-individual and between-place variation-a multilevel tutorial. Environment and Planning A, 29, 585-609.

Cao, C., \& Lam, N. S. (1997). Understanding the scale and resolution effects in remote sensing and GIS. In D. A. Quattrochi, \& M. F. Goodchild (Eds.), Scale in remote sensing and GIS (pp. 57-72). Boca Raton, FL: Lewis Publishers.

Cambridge Systematics, Inc. (1996). Data collection in the Portland, Oregon Metropolitan area case study. Washington, DC: US Department of Transportation.

Carrasco, J. A., \& Miller, E. J. (2006). Exploring the propensity to perform social activities: A social network approach. Transportation 33, $463-80$.

Chang, S. E. (2003). Transportation planning for disasters: An accessibility approach. Environment and Planning A, 35, $1051-1072$.

Fotheringham, A. S. (1989). Scale-independent spatial analysis. In M. Goodchild, \& S. Gopa (Eds.), The Accuracy of Spatial Databases (pp. 221-228). London: Taylor \& Francis.

Fotheringham, A. S., Brunsdon, C., \& Charlton, M. (2000). Quantitative geography: Perspectives on spatial data analysis. London: Sage.

Fotheringham, A. S., \& Wong, D. W. S. (1991). The modifiable areal unit problem in multivariate statistical analysis. Environment and Planning A, 23, 1025-1044.

Fujii, T., \& Hartshorn, T. A. (1995). The changing metropolitan structure of Atlanta, Georgia: locations of functions and regional structure in a multinucleated urban area. Urban Geography, 16, 680-707.

Gimpel, J. G., \& Schuknecht, J. E. (2003). Political participation and the accessibility of the ballot box. Political Geography, 22, 471-488.

Goldstein, H. (1998). Multilevel statistical models (second ed). London: Edward Arnold.

Gordon, P., Kumar, A., \& Richardson, H. W. (1989a). The influence of metropolitan spatial structure on commuting time. Journal of Urban Economics, 26, 138-151.

Gordon, P., Kumar, A., \& Richardson, H. W. (1989b). Congestion, changing metropolitan structure, and city size in the United States. International Regional Science Review, 12, 45-56.

Green, M., \& Flowerdew, R. (1996). New evidence on the modifiable unit problem. In P. Longley, \& M. Batty (Eds.), Spatial analysis: Modelling in a GIS environment (pp. 41-54). New York: Wiley. 
Hägerstrand, T. (1970). What about people in regional science? Papers of the Regional Science Association, 24, 7-21.

Handy, S. (1992). Regional versus local accessibility: neo-traditional development and its implications for non-work travel. Built Environment, 18, 253-267.

Handy, S. (1993). A cycle of dependence: Automobiles, accessibility, and the evolution of the transportation and retail hierarchies. Berkeley Planning Journal, 8, 21-43.

Handy, S., \& Niemeier, D. A. (1997). Measuring accessibility: An exploration of issues and alternatives. Environment and Planning A, 29, $1175-1194$

Hanson, S., \& Pratt, G. (1988). Reconceptualizing the links between home and work in urban geography. Economic Geography, 64, 299-321.

Haynes, R., Lovett, A., \& Sunnenberg, G. (2003). Potential accessibility, travel time, and consumer choice: Geographical variations in general medical practice registrations in Eastern England. Environment and Planning A, 35, 1733-1750.

Helling, A. (1998). Changing intra-metropolitan accessibility in the US: Evidence from Atlanta. Progress in Planning, 49, 55-108.

Hewko, J., Smoyer-Tomic, K. E., \& Hodgson, M. J. (2002). Measuring neighborhood spatial accessibility to urban amenities: Does aggregation error matter? Environment and Planning A, 34, 1185-1206.

Hillsman, E. L., \& Rhoda, R. (1978). Errors in measuring distances from population to service centers. Annals of Regional Science, 12, $74-88$.

Horner, M. W., \& Murray, A. T. (2002). Excess commuting and the modifiable areal unit problem. Urban Studies, 39, 131-139.

Jones, K., \& Duncan, C. (1996). People and places: The multilevel model as a general framework for the quantitative analysis of geographical data. In P. Longley, \& M. Batty (Eds.), Spatial analysis: Modelling in a GIS Environment (pp. 79-104). New York: Wiley.

Kawabata, M. (2003). Job access and employment among low-skilled autoless workers in US metropolitan areas. Environment and Planning A, 35, 1651-1668.

Kim, H.-M., \& Kwan, M.-P. (2003). Space-time accessibility measures: A geocomputational algorithm with a focus on the feasible opportunity set and possible activity duration. Journal of Geographical Systems, 5, 71-91.

Kitamura, R., Mokhtarian, P. L., \& Laidet, L. (1997). A micro-analysis of land use and travel in five neighborhoods in the San Francisco Bay Area. Transportation, 24, 125-158.

Kreft, I., \& de Leeuw, J. (1998). Introducing multilevel modeling. London: Sage Publications.

Kwan, M.-P. (1998). Space-time and integral measures of individual accessibility: a comparative analysis using a point-based framework. Geographical Analysis, 30, 191-217.

Kwan, M.-P. (1999a). Gender and individual access to urban opportunities: A study using space-time measures. The Professional Geographer, 51, 210-227.

Kwan, M.-P. (1999b). Gender, the home-work link, and space-time patterns of non-employment activities. Economic Geography, 75(4), 370-394.

Kwan, M.-P. (2004). GIS methods in time-geographic research: Geocomputation and geovisualization of human activities patterns. Geografiska Annaler B, 86, 267-280.

Kwan, M.-P., \& Hong, X.-D. (1998). Network-based constraints-oriented choice set formation using GIS. Geographical Systems, 5, $139-162$.

Kwan, M.-P., \& Weber, J. (2003). Individual accessibility revisited: Implications for geographical analysis in the twenty-first century. Geographical Analysis, 35, 341-353.

Limanond, T., \& Niemeier, D. A. (2003). Accessibility and mode-destination choice decisions: Exploring travel in three neighborhoods in Puget Sound, WA. Environment and Planning B, 30, 219-228.

Martin, D. (1996). Depicting changing distribution through surface estimation. In P. Longley, \& M. Batty (Eds.), Spatial analysis: Modelling in a GIS Environment (pp. 105-122). New York: Wiley.

Metro (Metropolitan Service District). (1997). Regional Framework Plan. Portland: Metropolitan Service District.

Miller, H. (1991). Modelling accessibility using space-time prism concepts within geographical information systems. International Journal of Geographical Information Systems, 5, 287-301.

Murray, A. T., \& Gottsegen, J. M. (1997). The influence of data aggregation on the stability of p-median location model solutions. Geographical Analysis, 29, 200-213.

Openshaw, S. (1978). An empirical study of some zone-design criteria. Environment and Planning A, 16, 17-31.

Openshaw, S. (1996). Developing GIS-relevant zone-based spatial analysis methods. In P. Longley, \& M. Batty (Eds.), Spatial analysis: Modelling in a GIS Environment (pp. 55-73). New York: Wiley.

Pickus, J., \& Gober, P. (1988). Urban villages and activity patterns in Phoenix. Urban Geography, 9, 85-97.

Pirie, G. H. (1979). Measuring accessibility: A review and a proposal. Environment and Planning A, 11, $299-312$.

Pooler, J. (1987). Measuring geographical accessibility: A review of current approaches and problems in the use of population potentials. Geoforum, 18, 269-289.

Recker, W. W., Chen, C., \& McNally, M. G. (2001). Measuring the impact of efficient household travel decisions on potential travel time savings and accessibility gains. Transportation Research A, 35, 339-369.

Ritsema van Eck, J. R., \& de Jong, T. (1999). Accessibility analysis and spatial competition effects in the context of GIS-supported service location planning. Computers, Environment, and Urban Systems, 23, 75-89.

Shaw, S.-L. (1991). Urban transit accessibility analysis using a GIS: A case study of Florida's Tri-Rail system. Southeastern Geographer, $31,15-30$.

Sheppard, E., \& McMaster, R. (Eds.). (2004). Scale and geographical inquiry: Nature, society, and method. Boston: Blackwell. 
Snellen, D., Borgers, A., \& Timmermans, H. (2002). Urban form, road network type, and mode choice for frequently conducted activities: A multilevel analysis using quasi-experimental design data. Environment and Planning A, 34, 1207-1220.

Subramanian, S. V., Duncan, C., \& Jones, K. (2001). Multilevel perspectives on modeling census data. Environment and Planning A, 33, 399-417.

Sultana, S. (2002). Job/housing imbalance and commuting time in the Atlanta metropolitan area: Exploration of causes of longer commuting. Urban Geography, 23, 728-749.

Talen, E. (1997). The social equity of urban service distribution: An exploration of park access in Pueblo, Colorado, and Macon, Georgia. Urban Geography, 18, 521-541.

Tobler, W. R. (1989). Frame independent spatial analysis. In M. Goodchild, \& S. Gopa (Eds.), The Accuracy of Spatial Databases (pp. 115-122). London: Taylor \& Francis.

Weber, J. (2003). Individual accessibility and distance from major employment centers: An examination using space-time measures. Journal of Geographical Systems, 5, 51-70.

Weber, J., \& Kwan, M.-P. (2002). Bringing time back in: A study on the influence of travel time variations and facility opening hours on individual accessibility. The Professional Geographer, 54, 226-240.

Weber, J., \& Kwan, M.-P. (2003). Evaluating the effects of geographic contexts on individual accessibility: A multilevel approach. Urban Geography, 24, 647-671. 